DOI: $10.15643 /$ libartrus-2015.3.3

\title{
Arguments and elements of realistic interpretation of mathematics: arithmetical component
}

\author{
(C) E. I. Arepiev*, V. V. Moroz \\ Kursk State University \\ 33 Radishchev St., 305000 Kursk, Russia. \\ *Email:arepiev@yandex.ru
}

\begin{abstract}
The prospects for realistic interpretation of the nature of initial mathematical truths and objects are considered in the article. The arguments of realism, reasons impeding its recognition among philosophers of mathematics as well as the ways to eliminate these reasons are discussed. It is proven that the absence of acceptable ontological interpretation of mathematical realism is the main obstacle to its recognition. This paper explicates the introductory positions of this interpretation and presents a realistic interpretation of the arithmetical component of mathematics. In summary, we should like to note that such constructions, as it is shown to us, ought to bring the direct use not only for the philosophical foundation of mathematics but for mathematics itself. In the justification of the author's conclusions based on the works of famous mathematicians of the twentieth century, interpreting their findings in a broad historical and philosophical context. To illustrate his point, the author gives examples of arithmetic and geometry - both Euclidean and non-Euclidean.
\end{abstract}

Keywords: implicit knowledge, mathematical knowledge, empiricism, mathematical realism, ontological and epistemological status of mathematical areas, interpretation of zero, natural numbers, non-Euclidean geometry.

The intuition that is the implicit knowledge of reality plays the significant role in the development of views on the nature of mathematics. The wording of the implicit knowledge can offer us the arguments in favor of one or another version. Why should we find the certain essential interpretation of mathematics the most acceptable? We consider the arguments of mathematical realism before discussing the specific details of the construction of the interpretation.

Speaking of truth criteria and defining their role in various areas of knowledge we partially reveal the ontological basis of these areas. We can choose empirical, rationalistic criteria or the criterion of practice as the main ones. Do the truths of mathematics correspond to reality? And if it's so what reality is it? Let's consider the connection of mathematical truths with main groups of truth criteria to clarify this question.

How is the mathematical knowledge associated with empiricism? It is known that the idea to recognize the mathematical propositions as the empirical knowledge finds its followers, with certain reservations and in different interpretations. But can we recognize the truths of mathematics as empirical generalizations, if it is not succeed to find examples to refute them empirically? Is it possible to imagine that the scientist faced with the contradiction between mathematical calculations and experimental data merely recognizes, for example, that sometimes two plus two equals five?

On the other hand, we cannot agree with those who argue that the truths of mathematics are in no way associated with the experience, neither confirm nor deny it, because they have no relation to reality but act only as a way of our knowledge. Firstly, mathematics often reveals abstract models of such areas of reality, the material world, which can be described by the natural sciences only after a 
considerable time. Secondly, the empirical criteria of truth indirectly confirm the laws and regulations of mathematics through their unfailingly efficient use in natural scientific understanding of the world.

The criterion of practice plays even more obvious evidence. If we understand practice as purposeful, planned and projected transformation of reality by human being, then, for example, the modern material production just loudly proclaims the truth of mathematical statements! Based on the mathematical concepts and laws we transform the world, and the success of this transformation obtaining the expected results confirms the satisfaction of our knowledge of reality. However, if empirical knowledge, principles and laws of the natural sciences can be refined with practice, the truths of mathematics can be confirmed with practice only, and this fact, again, tells us about their non-empirical nature.

Finally, when we talk about the rationalistic criteria as so logicality, consistency, argumentativeness of knowledge system, its orderliness, we need obviously to recognize that mathematics has not only a priority orientation on these criteria, but also acts as a standard of rational knowledge, serves as a source and indicator of scientific rationality criteria.

In our opinion, these criteria tell us about the truth of mathematical statements and their objective status, that is their belonging to being!

Many authors recognize the consequence of mathematical realism. V. V. Tselishchev shows that Platonism acts as the ontology for working mathematicians [1, p. 31-37], and we can not disagree that such philosophical foundation allows them to operate very successfully. M. Dummett notes the feature of the evolution of views of many thinkers, which consists in the final decision of the "complicated" realism [2, p. 472]. H. Putnam says about realism as one of the "basic intuitions". However, discourses about these arguments usually conclude with the system of counterarguments aimed to justify the rejection of realism.

The apparent absurdity of trying to explore some ideal world of mathematical entities is quite comparable with pessimism about the possibility of knowing the various components of the material world. This fact can be considered as realistic arguments from the history of science. For example, for a long time it was not impossible to research the micro-world and physical fields, although these investigations have been long anticipated with speculative philosophical constructs (atoms of Democritus, fluids of Descartes etc.). The history of science offers a variety of examples of mathematical anticipation. The mathematical results of N. I. Lobachevsky and other scientists preceded the recognition of curvature and varying the parameters of the physical space-time. The development of the theory of multidimensional spaces (Kaluza, Klein and others) considered a mathematical exercise devoid of physical meaning for about half a century also serves as an example. E. Wigner says about the presence of numerous anticipations in his famous article "The inconceivable effectiveness of mathematics in the natural sciences" [3, pp. 1-14].

The scientists have repeatedly addressed to develop new, unexplored areas such as transcendental and transfinite numbers, gravitation, electricity and magnetism, molecules, atoms etc. As we know, such researches proved to be very productive. Now apparently the problem of developing the program of mathematical realism is made before the philosophy of science in order to transfer the part of its problems and results to the concrete sciences later.

The problematic construction and lack of suitable ontological models are the significant factor hindering the recognition and consequently the development of realism. How do the objects and the truths of mathematics exist, where is this part of reality? This question remains central. It apparently can not be answered if we understand the reality as the material world only, if we contradistinguish the reality and possibility. To our opinion, it is necessary to understand the phrase "the possibility 
exists!" in literal sense for the decision of this question. Possibility is a part of the reality! Truths and objects of mathematics are the abstract expressions of universal laws of realized and still unrealized possibilities and all that is possible at all.

Now we consider a number of positions reflecting our understanding of the ontological and epistemological status of mathematical areas and mathematical knowledge in general. In these positions we try to express what mathematical truths and objects are and what their attitude to being and to the process of cognition are in the most simple and clear way.

First of all, in mathematical knowledge we can at least distinguish three areas the essential bases of which are not identical. It is, relatively speaking, the "arithmetical" component of mathematical knowledge based on the positions derived from cardinal and ordinal relations; the "geometric" component which operates with truths and objects that have spatial attributes; the "logical" component that is the set of areas engaged in expression of causation, conjunctive and other connections. In our opinion, non-identity of ontological and epistemological bases of these components of mathematical knowledge is quite evident on the present stage of the development of mathematics and its foundations.

Indeed, the history of ideas of logicism and Gödel's results convincingly show us the irreducibility of arithmetic to logic. Attempts to reduce the bases of mathematics (arithmetic) only to the laws of logic could not give the expected results except the results claiming inalienability of logical component in the essential foundation of mathematical knowledge. We can note that the problems of the definition of general and specific features of the two branches of logic - mathematical and philosophical - are largely due to the fact that the projection of mathematical logic into natural language began to work out much earlier than the "pure", mathematical logic or, if you like, the latter one began to develop in the unity with this projection. Logic developed in the projection on natural language that is to some extent similar to the way how the theory of probability developed implicitly projected onto the playing field of intellectual human activity. While other mathematical fields - geometry, arithmetic separated from their projections on nature and other areas in the early stages of their development.

So, the bases of arithmetical and logical components of mathematics are not identical. Likewise, this is the case with arithmetical and geometric components: heterogeneity of the numerical series and homogeneity of line, different types of intuition in these areas - all this (and much more) indicates the presence of the essential differences. As for the bases of geometric and logical components, the differences are also apparent as these areas have clearly different types of intuition (contemplative and rational ones, relatively speaking) and the sphere of the most effective applications (matter, space and mind, thought processes).

Thus, we can distinguish at least three basic components what allows to pre- make several theses into the scheme of the onto-epistemological interpretation of the foundations of mathematics.

1. All areas of mathematical knowledge based only on the positions derived from cardinal and ordinal relations are found on the initial, given a priori principles of mind. These principles are the possibility of its existence and related to the properties of reality (material, ideal, potential ones) expressed its continuous and discrete nature.

2. Geometric initial truths, or rather, the possibility of building a system of geometrical truths is also an integral part of mind expressed the universal, common forms of existence of the material world.

3. All branches of mathematical logic, that is the areas engaged in expression of causation, conjunctive and other connections, properties of the functioning of mind, the reasoning process 
are based on the necessary component of mind related to the expression in itself the possibilities of construction and operation of any system including mathematical ones.

Obviously all three components of the foundations of mathematical knowledge have extensive derivative areas in which these foundations intersect. However, these components are not identical but specific. Nevertheless the fact that they express the most general laws not only of all that exists, not only hypothetical, but all that is possible at all defines the very belonging to mathematics for all these areas.

As for the question of the relation of mind and the foundations of mathematical knowledge to being, it seems legitimate to assume that the mind belongs reality the extent to which all the possibilities of its development, transformation and existence relate to reality.

If we accept the above position as the initial installing hypothesis, we can try to develop a variant of the onto-epistemological interpretation of mathematics. It is necessary to structure mathematics and then justify, explain the elements of this structure gradually for building an interpretation of the foundations of this science. Having sketched above structuring as a basis, we assume that within the first, "arithmetical" component the numbers need for the explanation primarily. Together with the numbers, it is necessary explain many other mathematical concepts and objects for giving clarity to the foundations of this area. The explanation can be understood as the identification of philosophical, ideological, onto-epistemological sense in this case. Such detection has a visual analogue in the natural sciences, where, for example, so-called "physical sense" of a phenomenon or process is described, disclosed together with its mathematical description. However, it does not mean the possibility of identification of mathematics or its foundations with empirical sciences. Objects and the laws of mathematics, as opposed to objects and laws of nature sciences are neither abstractions from the empirically perceived objects and phenomena no derivatives of these abstractions.

In this regard we can call to mind that Frege indicates the impossibility of obtaining unit by abstraction from the Moon, for example, talking about the illegality of the interpretation of numbers as abstractions of objects. He also talks about the uncertainty of the object from which it is necessary to abstract for getting zero. "From what, exactly, is it necessary to abstract, for example, to go from the Moon to the number 1? ... 1 is not a concept, under which the Moon may fall. 0 has not even the object from which we start with abstraction" [4, p. 73]. There is some sense in such arguments of Pythagorean type, because they may help to clarify the essential epistemological status of numbers to some extent. Since the set of numbers is infinitive and they all have different properties, it would be logical to consider the question about the status of some of them - zero, one etc. or even the questions about the status of numbers corresponding to the figures, because ultimately they play a key role in the decimal counting system.

Similarly, we can use the Pythagorean arguments to series of other basic mathematical concepts. However, we can reveal a great deal of such concepts and consequently possible approaches. We try to start from the beginning that is from arithmetic and natural series of numbers. In our opinion, it should be given a particular attention to zero, one and two. Their specificity was observed earlier. For example, Frege states that "... the numbers themselves have their orders; each one is formed with its own way and has a peculiar, especially noticeable at 0,1 and 2." [4, p. 37]. Let's start from zero.

Zero can be interpreted as the mathematical expression of the possibility of existence. For example, when we the put zeros after the decimal point in the decimal fraction, it is understood that any figure or figures will stand after the zeros and there is the possibility of entering tenths, hundredths and etc. into this fraction but where there are zeros this possibility is not implemented. So the number 
0.046007 expresses, among other things, unimplemented possibilities of the presence of tenth, tenand one hundred thousandth. The number 0.201 contains a reference to the unimplemented possibility of the presence of hundredths. Similarly we can demonstrate the above arguments on natural, integer and other numbers: 104023008; -2453067; 4.(209) and etc. Zeros will point to the possibility of the presence of units, tens, hundreds and so ones till certain value depending on the number of digits in the number or on the possibilities of the presence of tenths, hundredths and etc. When children learn account teacher says that if from the basket, where there are five apples, they take two apples and then three apples more, there will be zero apples in the basket. The number of apples "zero apples" - indicates the possibility of their presence while the possibility of the presence of other objects, such as ships or meteorites is not implied.

Here is quite pertinent question of whether it would be more accurate interpretation of zero as a mathematical expression of unrealized possibility of the presence? In our opinion, the answer this question will be negative since, for example, the number 1000 consists of units, tens and hundreds, and the interpretation of zeros in it as unrealized possibilities of the presence creates ambiguity and contradiction. Thus zero as the mathematical expression of the possibility of existence without regard to the implementation of the possibility. It should be especially noted that the possibility can not be equated with the probability. Probability can be pre- defined as a quantitative expression of possibility. The very same possibility should be understood as the fundamentally permissible at all. For example, the probability to get a white ball out of the box containing only ten black balls is equal to zero, but it is acceptable in principle (Leibniz or Wittgenstein would say logically acceptable) that is possible, in our accepted sense of the word, in opposed to the outcome when we get a root ball or a triangular square. In this sense, the common name "impossible event" it would be better replaced by "an improbable event".

Let's continue our discussion with interpretation of the next number - one. One can be interpreted as a mathematical expression of the implemented possibility of the presence. For example, when we write the number 0.1 , we point out that the possibility of the presence a certain (tenth) of the share is implemented. When we write the number 10, it indicates the realization of the possibility of the presence a certain number (ten) etc. In principle, bearing in mind the possibility of translating the decimal to binary scale of notation, we could say that the essential foundation of numbers has been mainly marked. However, the possibility of reduction, as we know from a number of examples, does not mean identity of ontological and epistemological bases. Indeed, geometry, as noted above, has its own onto-epistemological bases other than arithmetical ones, although the geometric relations are translatable into numerical ones with a sufficient degree of completeness, thanks to the work of Descartes and others. B. Russell defines the geometry as a field of research of sequences of two or more dimensions that is a continuation of "pure mathematics" in Russell's terminology of trying to embody the idea of reducibility bases of mathematics to logic [5, p. 372]. In our interpretation, this definition reduces geometry to the arithmetical component of mathematics that does not correspond to the real situation, as already noted. Thus, reducibility decimal to binary scale of notation does not prescribe the necessity of limiting the components of the essential interpretation of numbers.

The illumination of the next number - dyad - as the mathematical expression of the availability of an alternative, variability, and ambiguity can serve its essential interpretation. For example, saying that the length of one segment longer than the other one or that ten more than seven, we specify only quantitative differences. However, the difference between one and dyad is also a qualitative differ- 
ence having the essential foundation. If one is the mathematical expression of the implemented possibility of the presence, but dyad is mathematical expression of the implement possibility (of the presence) of alternative, the availability of choice.

As for trine and other numbers corresponding fingers we need to acknowledge the absence (perhaps, temporarily) of a similar interpretation. However, most likely, this absence itself acts as interpretation in the sense that the natural numbers actually need three basic elements with the most strongly pronounced ontological specificity in this aspect of the essential features. Thus, natural numbers appear as a combination of expressions of the possibilities of the presence, implement possibilities and alternatives. It deals with numbers corresponding fingers and other numbers. Obviously, in this case, the decimal system is the most convenient and this "convenience" can not be considered random without good reason. Apparently, it is a consequence of not yet certain essential features of numbers.

At the end of this brief review, we should like to note that such constructions, as it is shown to us, ought to bring the direct use not only for the philosophical foundation of mathematics but for mathematics itself. However, a clear demand of the onto-epistemological interpretation of mathematical knowledge does not occur every day in all areas of science. It can manifest itself in its different sections, at peripheral areas where heuristic process is carried out, where it is not enough of tried and tested mathematical and the established notions to solve the problem. There are also periods in the process of the development of science when its extensive sections begin to need in the definition of the most suitable, adequate variant correlating their initial principles and settings with the reality and the process of cognition. For example, the period of the working-out of non-Euclidean geometry, the period of the creation and overcoming the crisis of "naïve" set theory and others appeared such a revolutionary step in the development of mathematics.

\section{REFERENCES}

1. Tselishchev V. V. Philosofija matematiki [Philosophy of Mathematics, in Russian]. Part 1. Novosibirsk: Nauka, 2002.

2. Dummett M. The interpretation of Frege's philosophy. London, 1981.

3. Wigner E. P. Communications on pure and applied mathematics. 1960. Vol. 13.

4. Frege G. Osnovopologeniya arifmetiki: Logiko-matematicheskoe issledovanie o ponyatii chisla [The bases of arithmetic: logical-mathematical study of the concept of number]. Tomsk, 2000.

5. Russell B. The Principles of Mathematics. 2nd td. London, 1937. 
DOI: 10.15643/libartrus-2015.3.3

\title{
Аргументы и элементы реалистического толкования математики: арифметическая составляющая
}

\author{
(C) Е. И. Арепьев*, В. В. Мороз \\ Курский государственный университет \\ Россия, 305000 г. Курск, ул. Радищева, д. 33. \\ *Email: arepiev@yandex.ru
}

Целью статьи является рассмотрение реалистического истолкования природы исходных математических истин и объектов. В статье обсуждаются аргументы реализма, препятствующие его признанию среди философов математики, а также способы устранения причин, обусловивших такую ситуацию. Эта статья эксплицирует вводные положения такого подхода и представляет реалистическую интерпретацию арифметической составляющей математики. Показано, что отсутствие приемлемой онтологической интерпретации математического реализма и есть основное препятствие такого признания. В статье разъяснены исходные положения этой интерпретации и представлена реалистическая интерпретация арифметической составляющей математики. В заключение хотелось бы отметить, что такие построения, как это показано нами в статье, могут быть использованы не только для философского обоснования математики, но непосредственно и в самой математике. При обосновании выводов авторы основывались на результатах исследований крупнейших математиков девятнадцатого века, интерпретируя их в широком историко-философском контексте. Свою точку зрения авторы иллюстрируют примерами из арифметики и геометрии - эвклидовой и неэвклидовой.

Ключевые слова: неявное знание, математическое знание, эмпиризм, математический реализм, онто-гносеологичсекий статус областей математики, интерпретация нуля, натуральные числа, неэвклидова геометрия.

Просьба ссылаться на эту работу как: Arepiev E. I., Moroz V. V. Arguments and elements of realistic interpretation of mathematics: arithmetical component // Liberal Arts in Russia. 2015. Vol. 4. No. 3. Pp. 198-204.

Поступила в редакцию 05.06.2015 2. 